\title{
Safe motherhood practices - Knowledge and behaviour among pregnant women in Belagavi, Karnataka. A descriptive study
}

\author{
Pooja S. Dhagavkar ${ }^{\mathrm{a}, *}$, Anita Dalal ${ }^{\mathrm{b}}$, Amit Nilgar $^{\mathrm{c}}$, Mubashir Angolkar ${ }^{\mathrm{a}}$ \\ ${ }^{a}$ Department of Public Health, Jawaharlal Nehru Medical College and Hospital, Belagavi, Karnataka, India \\ ${ }^{\mathrm{b}}$ Department of Obstetrics and Gynaecology, Jawaharlal Nehru Medical College and Hospital, Belagavi, Karnataka, India

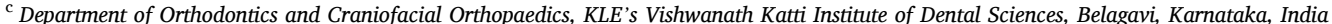

\section{A R T I C L E I N F O}

\section{Keywords:}

Behaviour

Knowledge

Pregnant

Safe motherhood practices

\begin{abstract}
A B S T R A C T
Background: Pregnancy and childbirth are essential for existence of the entire human race but maternal death is a twofold misfortune affecting both the mother and child. "Safe Motherhood Initiative" enlisted four pillars of safe motherhood but even after the launch of such and other initiatives maternal, infant and under 5 mortalities remained unacceptable. Assessing the level of awareness about safe motherhood practices among pregnant women thus becomes necessary to plan interventions to further empower them to avail these services.

Objective: To assess the level of knowledge and behaviour about the safe motherhood practices and factors influencing these practices in pregnant women.

Study group: Pregnant women attending antenatal clinic at a tertiary care hospital in Belagavi, Karnataka.

Methods: A questionnaire survey was conducted among 374 pregnant women for 4 months. Sociodemographic data and details of knowledge and behaviour about safe motherhood practices were collected using a predesigned pretested questionnaire. Data was analysed using SPSS software.

Results: Participants' mean age was 23.9 years. $84 \%$ of pregnant women had average knowledge while $68.4 \%$ had poor behaviour regarding Safe Motherhood Practices. Statistically significant associations were observed between knowledge and education level, employment status and socio-economic class, between behaviour and age at the time of marriage of the women and also between knowledge and behaviour (p-value $<0.05$ ).

Conclusions: Among pregnant women knowledge about Safe Motherhood Practices was average and behaviour was poor. There is a necessity to increase the knowledge which will in turn bring about a good behaviour and empower women to use the safe motherhood services.
\end{abstract}

\section{Introduction}

Pregnancy and childbirth are essential for existence of the entire human race but the complications involved in pregnancies often have a negative impact on mothers mentally, physically and emotionally. If a woman dies during childbirth the risk of death for children under five year doubles or even triples as seen in studies conducted in developing countries. Girls in particular are more affected. Thus, maternal death is a misfortune twofold. ${ }^{1}$

To prevent maternal mortality, morbidity and related adverse consequences the International Health Community including the World Bank, WHO, United Nations Population Fund and agencies in 45 other countries launched the "Safe Motherhood Initiative" in 1987 at a conference held in Kenya. ${ }^{2}$ This initiative enlisted four pillars of safe motherhood which included antenatal care, clean and safe delivery, essential obstetric care and post natal care including family planning. ${ }^{3}$

Since the launch of this initiative a fall in the maternal mortality rate was observed by nearly $44 \%$ over the past 25 years in $2015 .{ }^{4}$ The infant mortality rate reduced from an estimated rate of 64.8 deaths per 1000 live births in 1990 to 30.5 deaths per 1000 live births in $2016 .{ }^{5}$ There was also a decline in the number of under-five deaths from 12.7 million in 1990 to 5.9 million in 2015 . $^{6}$ Similar significant declines were observed in the maternal, infant and under 5 mortality rates in India as well. $^{6-8}$

Globally 800 women still die every day of preventable causes related to pregnancy out of which $20 \%$ is contributed by India, currently estimated to be 212 per 1,00,000 live births. ${ }^{9}$ Hence, in 2014 "Every Mother and Every Newborn" and in 2016, "The Global Strategy" were launched

\footnotetext{
* Corresponding author.

E-mail address: dhagavkar.pooja@gmail.com (P.S. Dhagavkar).
} 
to implement the 2030 agenda of Sustainable Developmental Goal (SDG)-3 to ensure healthy lives and promote well-being for all at all ages. $^{10}$

At the beginning of the Sustainable Developmental Goals era in 2016, the burden of pregnancy related preventable mortality and morbidity was still very heavy. ${ }^{11}$ Therefore it becomes necessary to assess the basic level of awareness about safe motherhood practices among pregnant women so that necessary interventions can be planned to increase their knowledge and empower them to avail these services.

There is a dearth of literature regarding this aspect in the Indian population while no study has been conducted in the Belagavi region of Karnataka. This study was therefore planned to assess the level of knowledge and behaviour about safe motherhood practices and factors influencing these practices in pregnant women.

\section{Methods}

A descriptive study was conducted including all pregnant women who attended the antenatal clinic at a tertiary care hospital, Belagavi from August 2016 to February 2018. Only those pregnant women who did not give consent were excluded from the study. Relevant permissions were obtained from the hospital authorities. Written informed consent was obtained from all the participants after briefing them about the study.

Sample size was calculated statistically using the formula $\mathrm{n}=\mathrm{Z}^{2} \mathrm{xp} \mathrm{x}$ $\mathrm{q} / \mathrm{d}^{2}$ where $\mathrm{n}=$ number of pregnant women to be sampled, $\mathrm{Z}=1.96, \mathrm{p}$ $=58 \%,{ }^{12} \mathrm{q}=100-\mathrm{p}=42 \%, \mathrm{~d}=$ margin of error $=5 \%$ which was 374 pregnant women.

A pilot study was conducted on $10 \%$ of the total sample i.e. 37 pregnant women who were excluded from the main study. Content validation of the questionnaire was done based on expert review. Necessary modifications were made based on the results of the pilot study and content validity. Data was collected using this pre-designed questionnaire.

This questionnaire was divided into 3 parts namely "personal and socio-demographic information", "back-ground information" and questions related to knowledge and behaviour about safe motherhood practices. The questionnaire consisted of 37 questions to assess knowledge and 27 questions to assess behaviour. For scoring every correct answer in knowledge section was awarded 1 mark while the wrong answer was given 0 mark, similarly behaviour questions were also scored with 1 for good behaviour and 0 for poor behaviour.

Ethical clearance from Institutional Ethics Committee (I.E.C.) was obtained for the study. Utmost care was taken to maintain the privacy and confidentiality of the study participants by confining their identity. Data was collected by the first author.

Data entry and analysis was done by using the statistical package for social sciences (SPSS) software version 20 and Microsoft Excel. Frequency and percentage were used to analyze the level of knowledge and attitude. Chi square test was used to find associations.

\section{Results}

Participants' mean age was 23.9 years, majority of the participants had completed their middle school (20.3\%), almost half of the participants were unemployed (53.7\%) and more than half of them (67.1\%) during their marriage were aged less than 20 years (Table 1 ).

Out of 374 participants, 314 (84\%) had average knowledge about safe motherhood practice with knowledge score 18-36.44 participants (11.8\%) had poor knowledge while only 16 participants $(4.3 \%)$ had good knowledge about Safe Motherhood Practices. $68.4 \%$ of the participants in this study reported poor behaviour while only $31.6 \%$ reported good behaviour (Table 2 ).

Knowledge score was assessed and statistically significant association was observed between the knowledge and education level of the participants, employment status and socio-economic class of the
Table 1

Socio demographic characteristics.

\begin{tabular}{|c|c|c|}
\hline Characteristics & Number & Percent (\%) \\
\hline \multicolumn{3}{|l|}{ Age (years) } \\
\hline$<20$ & 56 & 15.0 \\
\hline $20-25$ & 211 & 56.4 \\
\hline $25-30$ & 86 & 23.0 \\
\hline $30-35$ & 15 & 4.0 \\
\hline$>35$ & 6 & 1.6 \\
\hline \multicolumn{3}{|l|}{ Residential area } \\
\hline Peri-urban & 95 & 25.4 \\
\hline Urban & 279 & 74.6 \\
\hline \multicolumn{3}{|l|}{ Age at marriage (years) } \\
\hline$<20$ & 251 & 67.1 \\
\hline $20-25$ & 114 & 30.5 \\
\hline$>25$ & 9 & 2.4 \\
\hline \multicolumn{3}{|l|}{ Marital relation } \\
\hline Consanguineous & 97 & 25.9 \\
\hline Non consanguineous & 277 & 74.1 \\
\hline \multicolumn{3}{|l|}{ Education } \\
\hline Illiterate & 74 & 19.8 \\
\hline Primary school & 64 & 17.1 \\
\hline Middle school & 76 & 20.3 \\
\hline High school & 70 & 18.7 \\
\hline Intermediate & 37 & 9.9 \\
\hline Degree/PG & 53 & 14.2 \\
\hline \multicolumn{3}{|l|}{ Employment } \\
\hline Employed & 173 & 46.3 \\
\hline Unemployed & 201 & 53.7 \\
\hline \multicolumn{3}{|l|}{ Socio economic class } \\
\hline Lower & 0 & 00.0 \\
\hline Upper lower & 133 & 35.6 \\
\hline Lower middle & 134 & 35.8 \\
\hline Upper middle & 55 & 14.7 \\
\hline Upper & 52 & 13.9 \\
\hline \multicolumn{3}{|l|}{ Gravida } \\
\hline Primi & 153 & 40.9 \\
\hline Multi & 221 & 59.1 \\
\hline \multicolumn{3}{|c|}{ Age at first child (years) } \\
\hline$<20$ & 137 & 36.6 \\
\hline $20-25$ & 192 & 51.3 \\
\hline $25-30$ & 37 & 9.9 \\
\hline $30-35$ & 7 & 1.9 \\
\hline$>35$ & 1 & .3 \\
\hline Total & 374 & 100.0 \\
\hline
\end{tabular}

Table 2

Distribution of study participants according to their level of knowledge and behaviour.

\begin{tabular}{lll}
\hline Knowledge score groups & Number of participants & Percent (\%) \\
\hline Poor $(<18)$ & 44 & 11.8 \\
Average (18-36) & 314 & 84.0 \\
Good $(>36)$ & 16 & 4.3 \\
Total & 374 & 100.0 \\
\hline Behaviour score groups & Number of participants & Percentage (\%) \\
\hline Poor (0-9) & 256 & 68.4 \\
Good (10-18) & 118 & 31.6 \\
Total & 374 & 100.0 \\
\hline
\end{tabular}

participants ( $\mathrm{p}$-value $=0.000$ ) while it was not associated with any other socio-demographic variables. Behaviour score was assessed and statistically significant association was only observed between the behaviour score and age at marriage of the pregnant women ( $\mathrm{p}$-value $=0.013$ ) while it was not associated with any other socio-demographic variables (Table 3 ).

Statistically significant association was observed between the knowledge and the behaviour score (p-value-0.000). (Table 4 ).

\section{Discussion}

In this study out of 374 , more than half of the participants were in the 
Table 3

Association of knowledge and behaviour with socio-demographic variables.

\begin{tabular}{|c|c|c|c|c|c|c|}
\hline \multirow[b]{2}{*}{$\begin{array}{l}\text { Socio-demographic } \\
\text { variables }\end{array}$} & \multicolumn{3}{|l|}{ Knowledge } & \multicolumn{3}{|l|}{ Behaviour } \\
\hline & $\begin{array}{l}\text { Chi square } \\
\text { value }\end{array}$ & df & $\begin{array}{l}\mathrm{p}- \\
\text { value }\end{array}$ & $\begin{array}{l}\text { Chi square } \\
\text { value }\end{array}$ & $\mathrm{df}$ & $\begin{array}{l}\mathrm{p}- \\
\text { value }\end{array}$ \\
\hline $\begin{array}{l}\text { Age of participants } \\
\text { (years) }\end{array}$ & 9.984 & 8 & 0.266 & 8.089 & 4 & 0.088 \\
\hline Residential area & 0.193 & 2 & 0.908 & 1.031 & 1 & 0.310 \\
\hline $\begin{array}{l}\text { Age at marriage } \\
\text { (years) }\end{array}$ & 8.225 & 4 & 0.084 & 8.636 & 2 & 0.013 \\
\hline $\begin{array}{l}\text { Period of marriage } \\
\text { (years) }\end{array}$ & 9.349 & 10 & 0.499 & 8.930 & 5 & 0.112 \\
\hline Marital relation & 0.898 & 2 & 0.638 & 1.366 & 1 & 0.242 \\
\hline $\begin{array}{l}\text { Education of } \\
\text { participants }\end{array}$ & 39.527 & 12 & 0.000 & 4.715 & 5 & 0.452 \\
\hline Employment status & 16.059 & 2 & 0.000 & 1.461 & 1 & 0.227 \\
\hline $\begin{array}{l}\text { Socio economic } \\
\text { class }\end{array}$ & 36.752 & 6 & 0.000 & 5.748 & 3 & 0.125 \\
\hline Gravida & 0.175 & 2 & 0.916 & 2.015 & 1 & 0.156 \\
\hline $\begin{array}{l}\text { Age at first child } \\
\text { (years) }\end{array}$ & 6.877 & 8 & 0.550 & 6.929 & 4 & 0.140 \\
\hline
\end{tabular}

Table 4

Association between knowledge and behaviour.

\begin{tabular}{lllllll}
\hline \multirow{2}{*}{ Behaviour } & \multicolumn{2}{l}{ Knowledge } & Chi square value & df & p-value \\
\cline { 2 - 4 } & Poor & Average & Good & & & \\
\hline Poor & $84.1 \%$ & $68.2 \%$ & $31.2 \%$ & 15.250 & 2 & \multirow{2}{*}{$\mathbf{0 . 0 0 0}$} \\
Good & $15.9 \%$ & $31.8 \%$ & $68.8 \%$ & & & \\
\hline
\end{tabular}

age group of $20-25$ years (57.2\%) with the mean age being $23.9 \mathrm{yrs}$ and more than three quarters of them resided in the urban areas (74.6\%). In a similar study conducted in Nigeria on the knowledge of safe motherhood among women in rural communities the median age of the participants was 25 years and, in a study, conducted in Bangladesh the mean age of pregnant women was 24.61 yrs. ${ }^{13,14}$

Age at marriage also plays a vital role in reproductive health as well as in maintaining safe motherhood practices. In this study a large number of participants were married before the age of 20 years $(67.1 \%)$ and many had completed only 0-4 years for their marriage (74.6\%) also most of the participants had non-consanguineous marriages (74.1\%).

Education plays a major role to maintain safe motherhood practice. Data revealed that out of 374 participants $20.3 \%$ of the participants had only completed middle school while $19.8 \%$ of the participants were illiterate. The information reveals that participants did not have better education. The Nigerian study on knowledge of safe motherhood showed that half of the participants had received only Qu'ranic education $(58.1 \%$ and $50 \%) .{ }^{13}$ Economic activity is one of the strong indicators of national development. Occupation is also related with the economic activities. In this regard out of 374 participants almost half of the participants $53.7 \%$ were unemployed and more than half of them $71 \%$ belonged to the lower socio-economic class. Similar findings are shown in a study conducted in Bangladesh about knowledge and behaviour on safe motherhood practices where $92 \%$ of the participants were unemployed. ${ }^{14}$ These participants may not have sufficient money for purchasing nutritional food and antenatal, natal and postnatal service during pregnancy.

In the present study maximum of the participants (84\%) had average knowledge about safe motherhood practices and their knowledge score was $18-36.44$ participants (11.8\%) had poor knowledge while only 16 participants out of 374 (4.3\%) had good knowledge about Safe Motherhood Practices. These findings were similar to the study conducted within selected rural communities in northern Nigeria which showed generally poor knowledge about safe motherhood practices but among women who had recently delivered. ${ }^{13}$ They were also corresponding with those of a study done in Tribal Women of Selected four Tribal
Villages of Jambughoda Block, Panchmahal District, Gujarat showing that the overall knowledge regarding Safe Motherhood was low. ${ }^{15}$

In this study it was observed that the overall (68.4\%) behaviour was poor but this result is contradictory to a study conducted in tribal villages of Gujarat which showed good practices among the tribal women regarding Safe Motherhood practices. ${ }^{16}$

In this study it was seen that the knowledge regarding safe motherhood facilities was associated with their level of education, employment and socio-economic class. This result goes hand in hand with a safe mother hood knowledge study conducted in Nigeria which showed that knowledge of safe pregnancy practices among women in rural communities was strongly associated with, being employed and acquiring some level of education. ${ }^{13}$

Many other studies also show that knowledge regarding different aspects of safe motherhood like ANC, PNC, breastfeeding, obstetric danger signs, breast feeding etc. is associated with education status of women. ${ }^{13,17-21}$ It has also been seen that it is also associated with the socio-economic status and age at marriage in some other studies. ${ }^{19,20}$

Similar to this study a study done regarding the knowledge attitude and practice about ANC done in Pune showed that knowledge is not associated with parity. ${ }^{12}$

Educating and employing women will thus lead to increase in their knowledge about safe motherhood practices and empower these women to avail services which would translate into safer pregnancy outcomes and subsequently lead to lower maternal mortality across the developing world.

The present study revealed that behaviour of pregnant women was associated with their age at marriage. Majority of the participants were less than 20 years of age during their marriage and the behaviour was poor. If the age of marriage increases, it may improve the behaviour of these women regarding safe motherhood practices. In India a girl is supposed to complete 18 years of age for being able to get married this age limit needs to be revised if not raised so that the behaviour of women regarding their health during pregnancy improves. A study conducted in Bangladesh showed that knowledge and not behaviour had a significant association with age at marriage. ${ }^{22}$

Few other reported studies show that behaviour regarding various aspects of safe motherhood like ANC, PNC, breastfeeding, obstetric danger signs, breast feeding etc. had a significant association with age of the mother, education, employment, socio-economic status and parity which is not seen in this study. ${ }^{12,23,24}$

Knowledge of safe pregnancy practices among women in rural communities in Nigeria was strongly associated with behaviour like attendance at antenatal clinics. ${ }^{13}$ Also various studies conducted in Indonesia and Pune, India respectively showed that knowledge regarding contraception and ANC was associated with behaviour. ${ }^{12,25}$ These findings are similar to the current study which showed that the knowledge regarding safe motherhood practices was strongly associated with the behaviour of the women. This shows that to implement a better behaviour relating to safe motherhood definitely increase in the knowledge is required.

\section{Conclusion}

The participants had overall average to poor knowledge as well as poor behaviour regarding safe motherhood practices and because of their lack of knowledge and awareness they are not able to avail the safe motherhood services. The knowledge of pregnant women regarding safe motherhood had a strong association with their education level, employment status and socio-economic status, while the behaviour was strongly associated with age at marriage. The knowledge was also strongly associated with the behaviour. If women are given higher education which will enable them to seek employment and have a better socio-economic status the knowledge regarding safe motherhood may also increase. Also increasing the age at which girls are getting married may improve their behaviour regarding safe motherhood. Thus, if the 
knowledge increases it will lead to a better behaviour thus making pregnancy and delivery safer.

\section{References}

1 Garg BS, Chhabra S, Zothanzami S. Safe motherhood: social, economic, and medical determinants of maternal mortality. In: Women and Health Learning PackageTUFH Women and Health Task Force. second ed. 2006. pg.3.

2 World Bank Oxford University. World Developmental Report 1993-Investing in Health. New York: Oxford University Press; 1993.

3 World Health Organization. Mother-Baby Package: Implementing Safe Motherhood in Countries. Geneva: WHO Press; 2011.

4 World Health Organization. Trends in Maternal Mortality: 1990-2010 - estimates Developed by WHO, UNICEF, UNFPA and the World Bank 2012. Geneva: WHO Press; 2012:3.

5 World Health Organization. Global health observatory (GHO) data. Available from: http://www.who.int/gho/child_health/mortality/neonatal_infant_text/en/. Accessed $27^{\text {th }}$ Sept 2017.

6 United Nations Children's Fund. Levels \& Trends in Child Mortality Report. 2015:3 NewYork.

7 WHO, UNICEF, UNFPA, World Bank Group, and United Nations Population Division Maternal Mortality Estimation Inter-Agency Group. Maternal mortality in 19902015. Pg;1-5.

8 National Institute for Transforming India. Government of India. Infant Mortality Rate. Available from niti.gov.in/content/infant-mortality-rate-imr-1000-live-births. Accessed March 8, 2018. Accessed.

9 World Health Organization and UNICEF Count Down to 2015 Decade Report (20002010): Taking Stock of Maternal, New Born and Child Survival Geneva: WHO and UNICEF; 2010. http://www.childinfo. org/files/countdown Report 2000-2010.pdf. Available from: [Accessed 17th August 2017].

10 Every woman every child. Global Strategy for Women's, Children's and Adolescent's Health (2016-2030). Italy; 2015:10.

11 World Health Organization. WHO Recommendations on Antenatal Care for a Positive Pregnancy Experience. Geneva: WHO Press; 2016.

12 Patel B, Gurmeet P, Sinalkar DR, et al. A study on knowledge and practices of antenatal care among pregnant women attending antenatal clinic at a Tertiary Care Hospital of Pune. Maharashtra. Medical Journal of Dr. D. Y. Patil University. 2016;9(3): 354-362.
13 Okereke E, Aradeon S, Akerele A, Tanko M, Yisa I, Obonyo B. Knowledge of safe motherhood among women in rural communities in northern Nigeria: implications for maternal mortality reduction. Reproductive Health Journal. 2013;10(1):1-12.

14 Paneru D, Gyawali K, Jnawali B, Jnawali K. Knowledge and practices on maternal health care among mothers: a Cross sectional study from rural areas of mid-western development region Nepal. Journal of the Scientific Society. 2013;40(1):9-13.

15 Bhatta B. Public health awareness building in the field of safe motherhood. Journal of Nepal Health Research Council. 2009;6(2):69-73.

16 Pahad A, Sidhpura M, Somra T. Knowledge and practices regarding safe motherhood and new born care amongst tribal women of selected four tribal villages of Jamughoda block, Panchmahal district, Gujarat. Social Sciences International research journal. 3(1):136-138.

17 Igbokwe C, Obioma M, Igbokwe B. Safe motherhood practices among child bearing mothers (CBMs) in nsukka urban of enugu state, Nigeria. Journal of Applied Information Science and Technology. 2013;6:27-33.

18 Prasad S. Safe motherhood practice in dalit community. Academic Voices. 2012;2(1): 63-68.

19 Shafqat T, Fayaz S, Rahim R, et al. Knowledge and awareness regarding antenatal care and delivery among pregnant women. Journal of Medical Sciences Peshawar. April. 2015;23(2):88-91.

20 Osuchukwu E, Ezeruigbo C, Eko J. Knowledge of standard umbilical cord management among mothers in calabar south local government area, cross river state, Nigeria. Int J Nurs Sci. 2017;7(3):57-62.

21 Sangal R, Srivastava R, Singh A, et al. Knowledge and practices regarding obstetric danger signs in women attending antenatal care clinic at BRD medical College. Gorakhpur. Indian Journal of Preventive and Social Medicine. 2012;43(1):11-18.

22 Khan NJ. Knowledge and behavior on safe motherhood practice among pregnant mothers in rural area of Bangladesh. Int J Biosci. 2016;9(3):23-24.

23 Uppadhaya S, Bhansali S, Sivodia SK, et al. Utilization of postnatal care services in rural area of western Rajasthan, India. National Journal of Community Medicine. 2016; 7(7):569-572.

24 Choudhary AK, Bankwar V, Choudhary A. Knowledge regarding breastfeeding and factors associated with its practice among postnatal mothers in central India. Int $J$ Med Sci Publ Health. 2015;4(7):973-976.

25 Santoso B, Surya R. Knowledge attitude and practice of contraception among pregnant women in Ende district East Nusa Tanggara Indonesia. Journal of South Asian Federation of Obstetrics and Gynaecology. 2019;(2):110-118. 